\title{
Brief Analysis of Establishment of Effective English Classroom Teaching Model
}

\author{
Dingmin $\mathrm{Wu}$ \\ Yibin Vocational and Technical College \\ Yibin 644000, Sichuan, China \\ E-mail: wuyan6688@yeah.net
}

Received: December 27, 2011

Accepted: January 23, 2012 Published: April 1, 2012

doi:10.5539/ass.v8n4p281

URL: http://dx.doi.org/10.5539/ass.v8n4p281

\begin{abstract}
Classroom teaching is the major battle field for implementation of quality oriented education and the primary means of teaching is classroom teaching. Thus, it is a target that is constantly craved by the vast majority of education practitioners to study reform of classroom teaching, attempt to improve quality of classroom teaching, make limited classroom teaching hours give out unlimited vigor of life and enable students to really become the subject $\mathrm{f}$ learning. This article discusses effectiveness of improving English classroom teaching by analyzing the phenomenon and causes of low efficiency of classroom teaching, exploring practice of effective classroom teaching and improving efficiency of classroom teaching.
\end{abstract}

Keywords: Improvement, Effective classroom, Operation strategies

Effectiveness of classroom teaching is the lifeblood of teaching. What students learn, what improvements they have made and what development they have obtained are the issues that need to be taken into consideration in reform of English curriculum. Achievement of effective classroom teaching can not go without effective teaching strategies. As one of the subjects that have strong practicality, English has its peculiarity in the teaching strategies. In the process of teaching, teachers should employ scientific methods and strategies, effectively realize the teaching target, stimulate students' learning interests and enhance students' English level and capacity.

\section{Problems existing in English classroom teaching at present and the causes for these problems}

For the time being, reform of new curriculum is being propelled deeply and reform of classroom teaching has acquired substantial progress. However, as a result of inappropriate understanding and comprehending of the idea of new curriculum by the teachers and lack of necessary experiences and capacity among the implementers, the problems of formalization and low efficiency in reform of classroom teaching are becoming more and more obvious. And a large majority of students are still marking the time in their accumulation of knowledge and improvement of skills. As a result, what more input gets in return is less teaching effect. The problem of low efficiency in English classroom teaching has not yet been resolved and the problems of ambiguous teaching target and inappropriate teaching design still exist to a different extent. There are also some other problems, such as, ineffectiveness and low efficiency in cooperative learning, abuse of courseware and ignorance of practical efficiency, loose and low efficiency of classroom organizational rhythm. Classroom teaching is short of due living significance and life value and creativity of students is restrained. The reasons for all the above phenomena can be summarized as follows.

In the first place, the idea of teaching is outdated and the teaching target is ambiguous. The teaching idea guides and directs the teaching behavior. At present, some teachers fail to persist in the brand-new human oriented education idea that is required by the new curriculum aimed for all students and aimed at development of students. Instead, these teachers violate the subject idea that puts emphasis on communication, significance and application of language teaching. Since teachers have no appropriate understanding in the situation of students, they ignore that the teaching target should be specific and explicit, ignore the requirement of outcome goal, and merely lay special emphasis on language knowledge, ignoring the situational dialogue and cultivation of oral communication and the capacity of reading and comprehension. In the classroom, such phenomena may occur as perversion of difficulty and easy points, too much embedding, too difficulty points or too easy points. 
In the second place, design of teaching is not appropriate and teaching activities are blind. In terms of design of classroom teaching, although teachers attach importance to designing the target of language competence, the technique of target design is relatively laggard and defining of the target content is disorderly and ambiguous. Too much emphasis is put on grammar and vocabulary, choice of words and special cases of grammar. In classroom teaching activities, some teachers only rest content with a variety of group activities or competition activities with the purpose of publicity stunt. Group cooperation activities help to improve students' participation in language practice. However, not all teaching activities can be finished through group activities and usually group activities are not designed for perfect individual activities, such as, reading text and writing of short essay, etc. In the meantime, race to be the first to answer a question in a competition is also conducted in a chaotic situation.

In the third place, classroom organization management is low in efficiency and questioning of teachers is not appropriate. In terms of classroom organization, the phenomenon of misplacement of roles of teachers and students still exists and group activities are nothing more than something to create a lively atmosphere, remaining at formal hasty interaction and blind designing of group activities. For example, group activities are also designed for silent reading of text, which lacks rational operation methods. In terms of classroom questioning, some teachers do not take into consideration of reality of students and do not question with much concern. Their questioning lacks necessary foreshadowing and their means of questioning is too simple and repeated, which causes feedback of students seem somewhat redundant, just as in the case where several students answer one question at the same time. The questioning is not deep-going and what teachers finish is only a presupposed questioning, but they ignore the fact they can explore more information to question, which may give rise to lose of the opportunity of innovation among students.

\section{Establishment of effective English classroom teaching model}

\subsection{Design model of effective English classroom teaching model}

In the process of English teaching, the effective teaching model of the four aspects of "automatic learning, automatic development and vivid classroom" is implemented, namely, project setting --- project completion --project presentation --- project evaluation and stimulation.

The basic train of thought for design of this model is project setting --- project completion --- exchange and presentation --- evaluation and stimulation. This model uses the method of systematic analysis to analyze the "learning content" and "situation of students" and process appropriately the content. On that basis, teachers together discuss and decide whether the content of each class is defined as one or more projects, and then students finish the project and/or projects by individuals or in the form of group cooperation before the class starts or in the class. In the class, each group exchanges and presents the achievement and/or achievements of the project and/or projects and teachers give timely evaluation and stimulation on presentation of individuals or groups. This sort of classroom differs from the pattern of single knowledge impartation in the traditional classroom teaching of teachers lecturing and students listening and teachers speaking and students taking notes. In this sort of classroom teaching, students are required to participate within enthusiasm to reflect the initiative of students. Teachers should not only be concerned with what students are learning, but also concerned with how students can learn actively with joy and cultivating the innovative and explorative spirit of students.

\subsection{The basic framework of effective teaching model of the four aspects of "automatic learning, automatic} development and vivid classroom"

\subsubsection{Project setting (teacher behavior)}

"Project setting" refers to projectization of English text knowledge and constructs a "bridge" for transferring knowledge into capacity. In the process of completing a specific project task, the former knowledge and experience are applied and new knowledge is learnt in the process of detecting problems, analyzing problems and resolving problems. The basic requirement of project setting contains three aspects. Firstly, setting of a project has to be formed by collective preparation of instruction by a teaching and research group. Secondly, setting of a project has to be based on the precondition of fully studying the new "Curriculum Standard" and situation of students, with the core of knowledge focus in the subject and with the purpose of overall development of students' body and mind. Thirdly, the project setting should strive to be concise and enlightening, moderate in difficulty of content and stimulating students' interests.

\subsubsection{Project completion (students behavior as the major part, assisted by teacher behavior)}

"Project completion" mainly means that students complete a project by individuals or in the form of a group cooperation, in which students go into deep learning, training and evaluation in connection with the problems 
that have been discovered in "project setting", so as to resolve effectively the profound problems in the text course. "Project completion" is usually completed by teachers and students together. (1) This procedure requires teachers to convert their role. The role of teachers is converted from the traditional dominant player of teaching to the facilitator and assistor of teaching activities. In the process of teaching, teachers appear among students with the roles of a consultant, partner, friend and so on. The teaching method is transferred from an emphasis on "method of teaching" to an emphasis on "method of learning". Thus, in order to complete a teaching task, teachers have to make great efforts and energy. (2) This procedure requires students to participate actively. In the first place, students are required to have the consciousness of active participation. Students may encounter with a lot of problems in the process of learning, some of which can be resolved by reading the teaching material or a reference book, some of which can be resolved by mutual communication and discussion among students and some of which can only be resolved by direction and guidance of teachers. In the second place, students are required to have the capacity of discovering a problem, resolving a problem and comprehensive application of capacity. The learning process of students is finished by completing a specific project task. This specific task embeds teaching content into the task and makes the process of students completing the task not only one to learn the content of the text, but also one to apply the teaching content in an overall way. In that way, learning of knowledge and application of knowledge are combined together in an organic way. Secondly, students are required to focus on consciousness of grasping a method and innovative consciousness. The teaching method of project setting helps to cultivate the innovative consciousness and practical competence of students. In the process of project setting, teachers do not set any limitation to the method of completing a project or the form or content of the works finished, but only provide the materials that are required for completing a project. This leaves sufficient space for students to give full play to their imagination and free writing.

\subsubsection{Exchange and presentation (mainly students behavior)}

Exchange and presentation is to learn the thinking process and resolving method of a problem. Teachers are supposed to be good at organizing an interactive communication and encourage students to have positive thinking and let them share the achievements of learning through exchange and presentation. (1) Exchange and presentation has some requirements on students. In the class, students are required to write on the blackboard, make a presentation, exchange their ideas and give a speech, propose a question and interact with each other (with no limitation of the pattern and subordinate to the real need of teaching). First of all, the students who make a presentation are required to be loud and clear, with clear enunciation and teachers should listen to students and pay attention to their response. They are not supposed to frequently interrupt students' speech. Instead, they ought to pay attention to listening and summarizing. (2) Exchange and presentation has some requirements on teachers. Teachers should observe the answers to the questions of students' discussion and writing on the blackboard in the process of exchange and presentation, listen to the speech of students, further control the situation of students and consider adjusting the problems of interaction and the major points of lecturing and directing, etc. When teachers make evaluation on exchange and presentation of students, they ought to pursue the stage of "Not everybody is required to succeed, but everybody is required to make a progress." The purpose of that is to encourage students to take part in the exchange and presentation with enthusiasm and initiative, to build up a democratic atmosphere, advocate innovation of students and put all efforts to continuous progress and development of students.

\subsubsection{Evaluation and stimulation (mainly teacher behavior)}

"Evaluation and stimulation" is to give reflective and diversified evaluation on the learning effect and process of students in the process of learning so as to achieve the purpose of consolidating and strengthening knowledge and skills, perceiving knowledge and improving the significance of knowledge. Evaluation and stimulation can be fulfilled through the following four aspects. (1) In the first place, teachers centralize the problems that are collected in students' self-learning and presentation or give immediate direction or evaluation, for which the mode of interaction between teachers and students can be employed and teachers can also finish this alone. The process of direction can also be centralized in terms of the time and can also be conducted in the process of students' self-learning and presentation. In terms of content, in addition to encouraging and developmental evaluation, there should also be some direction and improvement of knowledge so as to enable students to obtain much in terms of knowledge and competence, etc. (2) Teachers may give students enough time to guide them in summary of a class and make students further clear about the major content of learning in the class. They can sort out the knowledge that has been learnt in the class to form a network pattern and give a test of classroom target-hitting in connection with the teaching target of the class and the topic designed. The topic of the test should focus on the important point, difficult points and points that are likely to make mistakes in the knowledge that has been learnt in the class, with moderate difficulty of content and appropriate amount of questions. (3) 
Teachers may propose a question or resort to other means to examine whether students are able to grasp the basic knowledge that is required to grasp in the class and present the network relation of the knowledge they have learnt. They should give feedback on the results in the class and make evaluation on performance of students in the class. When necessary, teachers can assign appropriate amount of homework to further consolidate the knowledge they have learnt. (4) In the aspect of testing, teachers should give a flexible test to test students' efficiency. Content of test can be either exercises that are intensively compiled or oral communication between teachers and students and between students and students, or extension and expansion of more profound knowledge and competence application of students. Teachers can resort to flexible and variable class testing to consolidate students' knowledge and further direct students to internalize and expand the knowledge they have learnt so as to achieve the effect of learning to meet practical needs.

\subsection{Strengthening teachers' reflection on classroom teaching}

1) Teachers in an effective classroom teaching must be reflective ones. Survey and analysis of behaviors in the process of teaching and the results generated thereby may enable teachers to continuously update their teaching concepts, improve their teaching behavior and enhance their teaching level. Reflection on teaching can be further divided into reflection prior to behavior, reflection in behavior and reflection after behavior in the process of teaching. Reflection can be realized by deciding whether project setting suits with the reality, whether implementation of project corresponds with the new teaching idea, whether project completion has resolved actual problems and whether classroom effect has achieved the anticipated target, etc.

2) Teachers are supposed to continuously reflect on their daily teaching behaviors. From preparation of teaching and classroom teaching, teachers can propose a series of questions with a rhetoric question. They can continuously ask "What kind of teaching is effective?", "Is my teaching effective?", "Is there any teaching that is more effective than my teaching?", "Do I always take an attitude of respect and encouragement towards my students?", "Do I feel that students have interest in learning content I choose?", "Which methods and means I often adopt to stimulate students' enthusiasm and interest and to encourage them to take an initiate in participating learning activities?", "Does my teaching design correspond with the understanding level and knowledge rules of my students?", "Is my teaching method enlightening and directive?", and "Is the space of thinking and training of competence I offer to my students enough?", etc. In this way, teachers can grow up continuously, obtain experiences in the practice of teaching and then apply these experiences in teaching and gain perfect teaching effect. These questions are not only reminding students, but also stimulating them, and meanwhile, leading teachers to continue to discover new problems in reflection and seek for approaches to resolve these problems.

\section{References}

Department for Basic Education under the Ministry of Education. (2004). The Idea and Innovation of New Curriculum. Higher Education Press.

Li, Jilin. (2002). Discussion on Classroom Operation Idea of Situational Education. Educational Research, (3), Wanfang Data, 127.

Xi, Zhen. (2011). Reform of Classroom Teaching Model and Establishment of High Efficiency English Classroom. Shanxi Education (Teaching Version), No. 6.

Xia, Huixian. (2001). Study on Contemporary Elementary and Secondary School Teaching Model. Guangxi Education Press.

Yao, Limin. (2008). Issues and Countermeasures in Effectiveness of English Classroom Teaching. English Teaching \& Research, No. 8.

Yu,Wensen. (2007). How to Improve Effectiveness of Classroom Teaching in New Curriculum. China Education Daily (6 ${ }^{\text {th }}$ ed.). China Education Resource Service Platform. [Online] Available: www.lersp.com 